\title{
El sarcófago de Amenirdis (Inv. -28104-). Apuntes en relación a su programa iconográfico y textual. Sitio de procedencia, datación y depositación
}

Mariano Bonanno*
Recibido:

5 de marzo de 2018

Aceptado:

12 de julio de 2018

\section{Resumen}

El sarcófago de Amenirdis es una de las piezas mejor conocidas de la colección egipcia del Museo Etnográfico de Buenos Aires. El nombre de su propietario es la nb.t pr Amenirdis. Aunque no es excepcional en su decoración y factura, presenta algunas cuestiones interesantes relacionadas con su contexto social y material, así como con las apropiaciones por particulares de diversos motivos iconográficos y textuales de transfiguración de la realeza. Además, el sarcófago es analizado como la expresión material de la movilidad socioeconómica de ciertos estratos de la sociedad.

The sarcophagus of Amenirdis (Inv. -28104-): Notes on its iconographic and textual data - place of origin, dating and deposition

\begin{abstract}
The sarcophagus of Amenirdis is one of the better-known objects in the Ethnographic Museum of Buenos Aires's Egyptian collection. The name of its owner is that of $n b . t p r$ Amenirdis. Although it is not exceptional in so far as its decoration or manufacture is concerned, it does present some interesting questions related to its social and material context; as well as the appropriation of certain textual and iconographic motifs associated to royal transfiguration. In addition, we analyze the sarcophagus as the material expression of the socioeconomic mobility inherent to certain social strata.
\end{abstract}

\section{Palabras clave}

Sarcófago Iconografía Amenirdis Regeneración Depositación
Keywords

Sarcophagus Iconography Amenirdis Regeneration Deposition 
1. El sarcófago fue posiblemente donado por el gobierno francés en la primera mitad del siglo XIX.

2. Actualmente lleva el nombre de Instituto de Historia Antigua Oriental "Dr. Abraham Rosenvasser".

3. El sarcófago es asimilado con la protección de la madre y con la promesa de regeneración representada por Nut. Según Piankoff (1934, p. 57): “Nut, la diosa del cielo, deviene en protectora del muerto, personificación del sarcófago; y como el sol, que estaba durante la noche en el cuerpo de la diosa del cielo Nut, el muerto en su sarcófago era concebido otra vez en una nueva y más gloriosa existencia".

4. La compleja relación entre el cuerpo y el ba -traducido habitualmente como "alma"-, marca el pulso de los procesos recurrentes de unión-disociación-(re)unión, que es la que delinea la ciclicidad característica del mundo funerario y sus habitantes, activados por el ritual. La separación y/o destrucción de uno de sus componentes supone la aniquilación o la imposibilidad de seguir o unirse al séquito de $R a$.

5. Para los antiguos egipcios, el Más Allá era la continuación de la vida, simplemente con un cambio de forma de un cuerpo mortal a un espíritu inmortal. Por ello, los egipcios se preparaban para el Más Allá, al equipar las tumbas con todos los objetos esenciales para asegurar la supervivencia de su espíritu para la eternidad (Valentine, 2013).

6. Los sarcófagos rectangulares o qrsw son un cosmograma que servían para perpetuar un número de episodios que se creían eran vitales para el renacimiento del difunto. La selección de textos y su disposición es seguramente una indicación de que los sarcófagos orsw representaban la cámara sepulcral, (Greco, 2014, p. 193). Los ejemplos de este tipo se caracterizan por una tapa abovedada y postes en sus esquinas.

7. O sxw.Ya entre la XII y XII Dinastías, los primeros cofres antropomorfos exhiben una manufactura en madera

o en cartonagge, Taylor (1989, p. 24). Ello confirma la "movilidad estilística" de los tipos de sarcófagos.

\section{Introducción}

La historia del estudio del sarcófago de Amenirdis ${ }^{1}$ comienza en el año 1972, cuando la Dra. Fuscaldo lo presenta en el primer número de la Revista del Instituto de Historia Antigua ${ }^{2}$ de la Facultad de Filosofía y Letras (FFyL) de la Universidad de Buenos Aires (UBA), juntamente con otras piezas de la colección egipcia del Museo Etnográfico "J. B. Ambrosetti" de la FFyL de la UBA. Con una foto de la tapa dividida en los seis registros que la componen y su descripción respectiva, el artículo se completa con copias de los jeroglíficos y la traducción al español (Fuscaldo, 1972). Con posterioridad, el sarcófago fue objeto de varios análisis por parte de Diego Santos (2003, 2007) en los números 11 y 12 de la revista Aegyptus Antiqua, publicada por el Centro de Estudios de Egipto y del Mediterráneo Oriental (CEEMO) de la Ciudad de Buenos Aires. Allí el autor realiza una nueva traducción, esta vez con la transliteración correspondiente. En líneas generales, no se observan mayores diferencias con respecto a la traducción de la Dra. Fuscaldo, pero en lo que respecta a la historia del objeto se incluye un trabajo de investigación sobre su derrotero hasta su destino final en el Museo Etnográfico.

\section{Respecto de los sarcófagos}

El término "sarcófago" tiene su origen en el griego $\sigma \alpha \rho \kappa o \varphi \alpha ́ x o \varsigma$, palabra compuesta por $\sigma \alpha \rho \kappa о \varsigma$ у $\varphi \alpha \gamma \circ \varsigma$, que podría traducirse como "devorador de la carne" o "devorador del cuerpo". Según Küffer (2012, p. 4), uno de los conceptos de la palabra "ataúd" en egipcio antiguo era "embrión en el vientre materno"3. El término es usado habitualmente en egiptología para designar el contenedor hecho a los efectos de proteger el cuerpo momificado del propietario.

Como parte del ajuar funerario el sarcófago ocupaba un lugar central, dado que en y desde su interior se activaba la interacción ontológica ${ }^{4}$ de la vida egipcia en el Más Allá . $^{2}$ Su función era proteger el cuerpo de la descomposición debido a que su preservación era fundamental para la continuidad de las funciones vitales en la muerte. Según las creencias de los egipcios, "la muerte se consideraba el umbral de una nueva vida en un ámbito del más allá” (Küffer, 2012, p. 1).

Su importancia fue variando a lo largo del tiempo y para la época en que se fecha el sarcófago de Amenirdis (ver sección Datación y tipología de la iconografía), "la variedad de elementos que se colocaban en la tumba era mucho más reducida" (Taylor, 2001a, p. 225). Incluso el diseño de los sarcófagos fue variando, desde las formas rectangulares más antiguas hasta los últimos sarcófagos antropomórficos del Egipto romano. Manteniendo un diseño estándar hasta fines del Reino Medio, "la introducción de divinidades o textos funerarios o de ofrendas fue enriqueciendo y complejizando la tipología de los sarcófagos" (Dodson, 2015, p. 4).

La materialidad del sarcófago plasma no solamente la capacidad económica del poseedor sino también su posicionamiento social y su vinculación con alguna institución religiosa. Esta materialidad ha sido delineada como un concepto multifacético: un medio de explorar tanto la "inmaterialidad”, detrás de lo cual está lo que es real, y la "mutualidad", la miríada de medios por los cuales la cultura interviene en el ser social.

El uso del sarcófago tiene su origen en el Reino Antiguo, siendo la forma rectangular la predominante ${ }^{6}$. A fines de la Dinastía XI o principios de la Dinastía XII comienzan a aparecer los sarcófagos antropomorfos, denominados $s x w$ (saju) ${ }^{7}$ que "parecen constituir una evolución de la máscara funeraria colocada sobre la momia" (Sousa, 
2011, p. 233). La tipología de los sarcófagos es rica y variada ${ }^{8}$. A modo de ejemplo, y dado que su especificidad excede los límites de este trabajo, la Tabla 1 expone los tipos más significativos.

\section{Materiales y medidas del sarcófago de Amenirdis}

La propietaria del sarcófago es mencionada en el programa textual como la nb.t-pr Amenirdis. Según el Wörterbuch der ägyptischen Sprache (Wb), el título hace referencia a la Señora de la Casa - Herrin des Hauses-, como al título de esposa - Titel der Ehefrau-, y puede ser inseparable del nombre, como en el caso de nuestro sarcófago. El título de "Señora de la Casa” era el más común de los títulos femeninos e involucraba la dirección del hogar y el cuidado de los niños así como de una familia nuclear o extensa. Aparte de ello, las mujeres de todos los estratos sociales eran definidas como esposas y madres primero y por encima de todo. Es por ello que tanto nb.t-pr como $x k r$.t nsw ("ornamento real") parecen expresar una afiliación y un status social o marital más que una ocupación.

El sarcófago de Amenirdis es un sarcófago interno antropomorfo ${ }^{9}$, bivalvo, con pedestal $^{10}$, de madera de sicómoro ${ }^{11}$, en pintura polícroma, que representa al difunto llevando una peluca tripartita. Probablemente, este sarcófago y otros similares tal vez hayan sido "producidos en masa (...), extraídos de un solo tronco de madera" (Lacovara, 2007, p. 35). Desde la Dinastía XXV se hacen comunes los sarcófagos con un pie o pedestal con el objeto de simplificar el rito de Apertura de la Boca e inversamente se hace uso cada vez más aislado de la técnica del cartonagge.

La tapa del sarcófago se encuentra en buen estado de conservación, no así su caja, y los colores conservan su brillo original más allá de una destrucción relativa en la decoración de ambos hombros. El hombro derecho presenta un orificio bastante grande, de aproximadamente $23 \mathrm{~mm}$, que, con un par izquierdo, cumplía la función de sujetar la tapa a la caja del sarcófago. En la Tabla 2 se ofrecen las principales medidas de la tapa, mientras que la Tabla 3 complementa la anterior con datos adicionales, además de referencias relativas a la coloración de la misma.

\section{La tapa externa del sarcófago (inventario)}

La tapa del sarcófago de Amenirdis consta de seis registros decorados (Figura 1) con una menor profusión de textos en relación con su iconografía. Los sarcófagos internos de las Dinastías XXV y XXVI presentan en la tapa una decoración que imitaba la de los períodos más antiguos, en combinación con características nuevas, con una gran concentración de decoración, colores brillantes y "más constricción en los registros" (Valentine, 2013, p. 16).

La tapa de este sarcófago interno antropomorfo en pintura polícroma ${ }^{12}$, que representa a la difunta llevando una peluca tripartita ${ }^{13}$, presenta debajo de esta, inmediatamente en la parte inferior, un amplio collar y un sol alado. A continuación comienzan los registros. Tal como se presenta en la Figura 1, cada uno de ellos se superpone secuencialmente, sin una línea vertical rectora en torno a la cual se disponen. De este modo, cada registro puede leerse e interpretarse sin necesidad de vincularlo con el siguiente o el precedente, más allá de lo que este conlleva.

Los seis registros de la tapa se distribuyen de la siguiente manera:

I. La diosa Nut con sus alas desplegadas en actitud de protección al difunto. Debajo se representa la puerta de entrada al otro mundo en cuyos flancos se ubica Amón en su
8. Para una sinopsis de la evolución, tipología y cambios en la decoración de los sarcófagos a lo largo de la historia egipcia, ver Cooney (2014, pp. 269-292); ver Dodson (2015, p. 4-5). Para una sinopsis de las características de sarcófagos tardíos, ver http://www.fitzmuseum.cam. ac.uk/tt9g/reportg9/coffins.html. Para una tipología de sarcófagos de la época de Nectanebo en función de su iconografía relacionada a los Libros del Más Allá del Reino Nuevo, ver Manassa (2007).

9. Los denominados sarcófagos "internos" eran los que estaban en contacto directo con la momia.

10. Un pedestal representa la parte más baja de la parte compuesta de sarcófago interno antropomórfico colocado bajo los pies. Su forma es generalmente rectangular, con un estrecho interior del pie. El pedestal en sí mismo está físicamente dividido en dos partes conectadas inseparablemente al resto del sarcófago. Una está conectada con la tapa, mientras que la otra pertenece a la depresión - parte curva baja- y está físicamente dividida en dos partes inseparablemente conectadas al resto del sarcófago (Magdolen, 2015).

11. "El antiguo Egipto no fue bendecido con maderas de alta calidad, con artesanos confiando en una acacia nativa (Acacia), en un sicomoro (Ficus sycomorus) o en un tamarisco (Tamarix aphylla). Las propiedades especiales de ciertas maderas importadas, especialmente coníferas tales como el cedro

(Cedrus), eran, sin embargo, bien conocidas y altamente codiciadas desde comienzos del cuarto milenio BC" (Chiou y Sowada, 2009, p. 27).

12. "El exterior de los sarcófagos de esta época es invariablemente polícromo. El fondo de estas escenas era usualmente blanco o amarillo" (Taylor, 2001a, p. 174).

13. Este tipo de peluca, también conocida como peluca "orejera", es uno de los tipos de peinados más antiguos usados por reinas. Esta puede haber sido usada lisa, como es característica en las diosas en el Reino Nuevo, o en rizos superpuestos o trenzas, pero su característica principal es la división del cabello en tres secciones. Estas pueden terminar en mechón o trenza, o en el caso de las pelucas lisas, en un borde horizontal, a veces con elementos decorativos en la forma de un uraei (Green, 1988). 


\begin{tabular}{|l|l|}
\hline Tipo de sarcófago & Datación \\
\hline Rectangulares & Reinos Antiguo (2543-2120 A.D.) y Medio (1980-1760 A.D.) \\
Anidados (nested) & $\begin{array}{l}\text { Reino Antiguo en adelante } \\
\text { Reino Medio en adelante }\end{array}$ \\
Antropomorfos & $\begin{array}{l}\text { Desde la Dinastía XIII (1759-1630 A.D.) } \\
\text { Rishi (Miniaci 2007, 2010) }\end{array}$ \\
Blancos & $\begin{array}{l}\text { Comienzos de la Dinastía XVIII (1539-1292 A.D.) } \\
\text { (1190-1077 A.D.) }\end{array}$ \\
Negros & $\begin{array}{l}\text { A partir de Amenofis III (1390-1353 A.D.) } \\
\text { Amarillos }\end{array}$ \\
Once-once (Elias 2014) & $\begin{array}{l}\text { Período Saíta (664-525 A.D.) } \\
\text { Cartonagge }\end{array}$
\end{tabular}

Tabla 1. Evolución de los sarcófagos egipcios.

\begin{tabular}{|l|c|c|c|}
\cline { 2 - 4 } \multicolumn{1}{c|}{} & \multicolumn{3}{c|}{ Medidas de la tapa (cm) } \\
\cline { 2 - 4 } \multicolumn{1}{c|}{} & Por los pies & Por los hombros & Por la cabeza \\
\hline Ancho & 32 (min.) & 52 (máx.) & 31 (cuello) \\
Altura & 29 (máx.) & $\begin{array}{c}\text { Ambos hombros } \\
\text { dañados }\end{array}$ & 22 (nariz) \\
\cline { 2 - 4 } Largo & \multicolumn{3}{|c|}{182} \\
\hline
\end{tabular}

Tabla 2. El sarcófago. Medidas del sarcófago según el método empleado por van Walsem (1997, p. 36) para el sarcófago de Djedmonthuiufankh en el Museo Nacional de Antigüedades de Leiden. Nota: El estado de conservación de la base hace imposible la toma de medidas.

\begin{tabular}{|c|c|}
\hline \multicolumn{2}{|r|}{ Otras medidas adicionales } \\
\hline Cabeza & $20 \mathrm{~cm}$ de alto \\
\hline Espesor de la pared del pedestal & $3,50 \mathrm{~cm}$ \\
\hline Pedestal & $\begin{array}{l}30 \mathrm{~cm} \text { de alto y } 39 \mathrm{~cm} \text { de ancho } \\
\text { (falta un segmento del lado derecho) }\end{array}$ \\
\hline Alto de hombros & $8 \mathrm{~cm}$ \\
\hline \multicolumn{2}{|r|}{ Coloración de la tapa } \\
\hline Cara & adornada, con cejas y párpados negros \\
\hline Peluca & dorada y marrón claro \\
\hline Banda del lóbulo & negra \\
\hline "Tirante" & amarronado, con líneas y cuadros azules, rojas y doradas \\
\hline Cuello & dorado y rojo sobre fondo azul \\
\hline Pintura general & Líneas divisorias amarillas entre los registros \\
\hline
\end{tabular}

Tabla 3. Otras características adicionales específicas según el esquema utilizado por Bolshakov (1992) para el análisis específico de la coloración de un cartonnage del Museo Hermitage de San Petersburgo.

forma de carnero sobre un pedestal. Junto a Amón, sobre la derecha, aparecen Amset, y sobre la izquierda, Kebekhsenuf, ambos hijos de Horus (dos de los vasos canopes que contenían el hígado y los intestinos del difunto, respectivamente). 


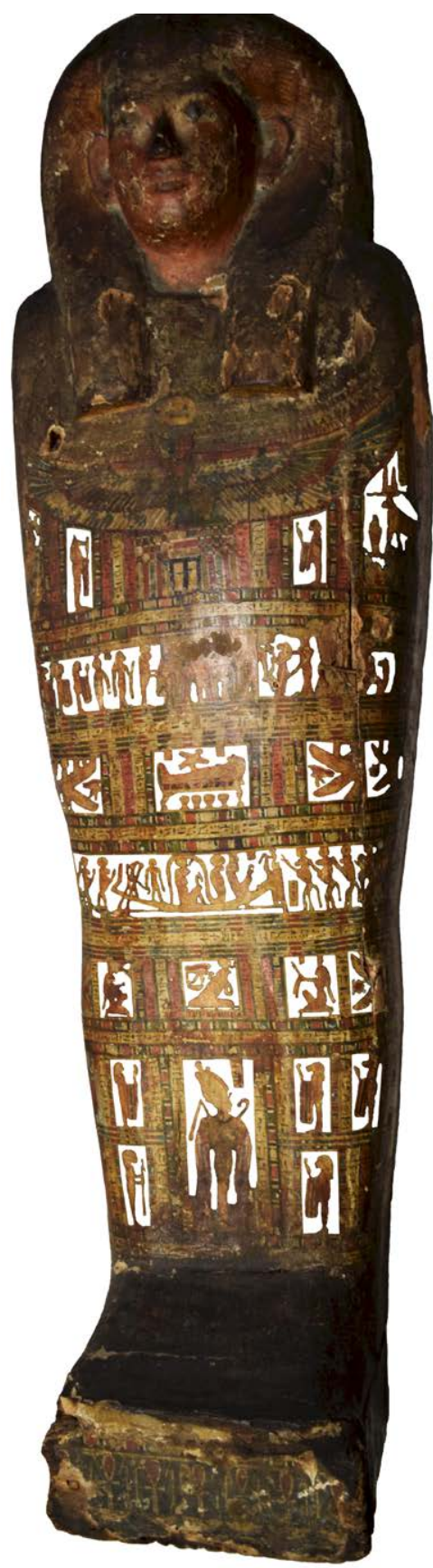

Figura 1. La tapa del sarcófago de Amenirdis.

II. Se representa al difunto y a sus padres frente a Osiris. Detrás del dios de los difuntos, sobre al lado izquierdo se encuentran Horus, Isis, Neftys, una divinidad no identificada y los cuatro hijos de Horus (Hapy, Duamutef, Amset y Kebekhsenuf). Sobre el lado derecho, se representa a la balanza que representa el pesaje del corazón del difunto en el juicio a los muertos.

III. El tercer registro se compone de tres escenas. Entre dos figuras de Horus y Nekhbet en los extremos izquierdo y derecho respectivamente, el $b A$ (ba) en su forma de ave se posa sobre el ataúd que contiene el cuerpo momificado. Debajo aparecen los cuatro vasos canopes. 
IV. La escena del cuarto registro de la tapa está dominada por una barca en cuyo centro aparece Horus con el disco sobre su cabeza y rodeado por una serpiente. Delante de la barca aparece la figura de una diosa mAat (Maat) mientras que en la parte trasera se aprecia a su timonel. En la proa, se ve una esterilla coronada con la figura de un niño con flabelo (el sol), mientras que tanto por delante como por detrás de la barca, se hallan nueve babuinos con el disco sobre sus cabezas, que levantan los brazos en señal de adoración.

V. El protagonismo del quinto registro es de la figura de un Horus momificado - Horus de Nekhen- detrás del que hay uno ojo wDA.t (udjat), a la izquierda está Neftys y a la derecha un Horus delante del cual hay un signo $S n$ (shen).

VI. En el último registro, la figura central es Osiris con sus insignias características, la corona Atf (atef), el cayado y el látigo. A ambos costados, se hallan los cuatro hijos de Horus y dos divinidades desconocidas, una de las cuales lleva el cetro $w A s$ (uas) y la otra, la pluma de mAat.

Pedestal. La parte frontal del pedestal se encuentra en muy buen estado de conservación, no así los laterales y su parte trasera. Los signos que decoran el frente del pedestal siguen la secuencia anx-wAs-wAs-anx. Los contornos de los signos son amarillos y en el caso del anx (ankh) la parte redondeada está pintada en rojo, ambos signos están representados sobre un fondo azul oscuro. Las connotaciones de los signos están dadas por lo cada uno de ellos simboliza: poder y dominio (sobre la muerte) en el caso del cetro $w A s$ y vida (en la muerte) en el caso del signo anx.

\section{Programa textual del sarcófago de Amenirdis}

A la hora del análisis textual e iconográfico, no debemos olvidar que todo el arte egipcio, especialmente el funerario, es performativo, con cada imagen y con "cada jeroglífico funcionando para traer una realidad deseada" (Cooney, 2010, p. 232). Las particularidades del sarcófago de Amenirdis, no tanto en su iconografía sino en su programa textual, crean un contexto eminentemente performativo, por cuanto la condición sine qua non para la re-creación de las ofrendas, temática que prevalece en el sarcófago, así lo requiere.

En determinadas temáticas, tales como la objetivación de alimentos, bebidas y ajuar para el difunto en general, la carga performativa es ostensible. Si tenemos en cuenta que el muerto requería de ofrendas y que estas eran organizadas por los vivos, el caso de Amenirdis plantea y re-significa la performatividad. Las limitaciones y recursos que entendemos rodean al sarcófago y su entorno general confieren menos gravitación al papel de los vivos como activadores de ofrendas.

La grafía no es de una factura de calidad, quizás por tratarse de jeroglíficos escritos con trazos ligeros (Figura 2) sin los detalles de la escritura de jeroglíficos tradicionales, razón por la cual se denomina a este tipo de escritura como jeroglífico "cursivo" o "lineal". Los signos no son uniformes y hay variaciones de un mismo signo en tamaño y forma. Si bien ello puede deberse a cuestiones vinculadas con el espacio, si comparamos algunas secciones de la tapa con las de la caja, dan la impresión de haber sido hechos por diferentes artistas. La posibilidad mencionada anteriormente de una producción "en masa" de los sarcófagos pudo haber supuesto el uso de un artista para la tapa y otro para la caja, aunque solo se trata de una hipótesis. Los jeroglíficos de la tapa son líneas negras rápidas sobre fondos alternados rojo y dorado separados por líneas azules y ocasionalmente líneas tricolores (verdes rojas y azules). Los de la caja, por su parte, son de color negro sobre fondo blanco. Por otro lado, los textos del sarcófago de 


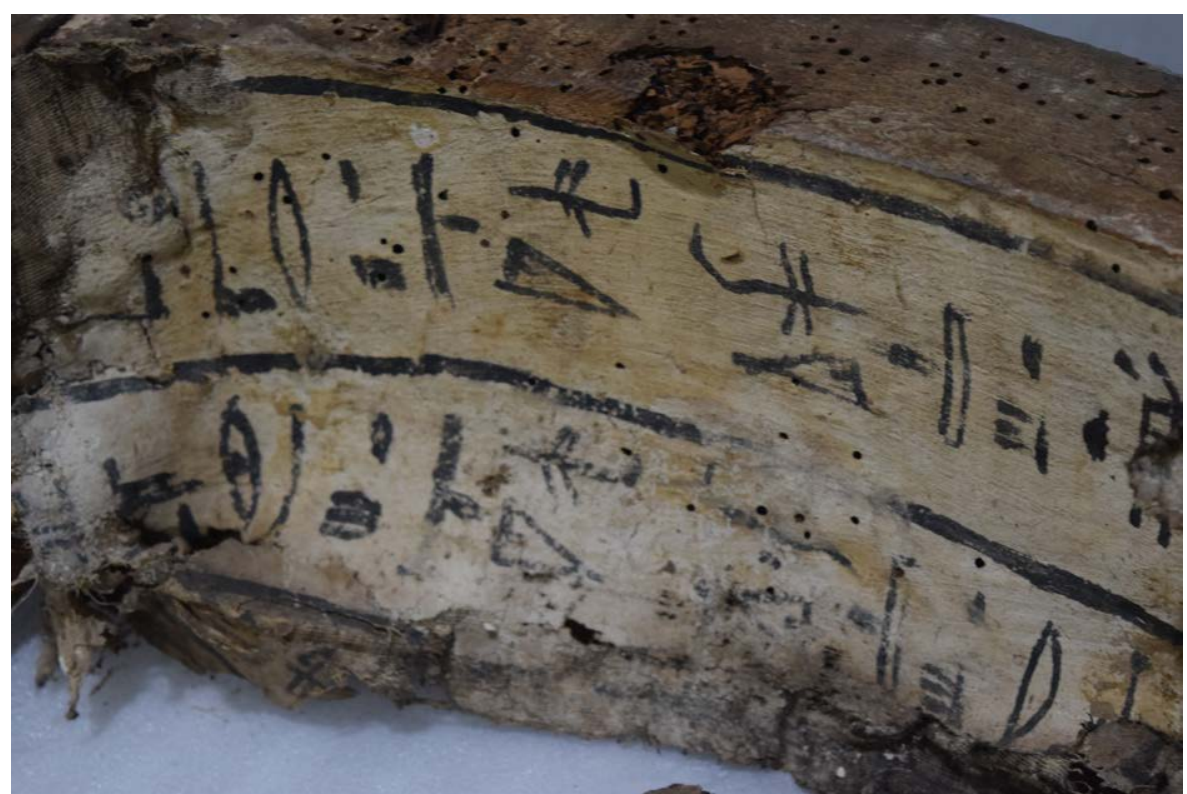

Figura 2. Detalle de la escritura en la caja del sarcófago de Amenirdis.

Amenirdis - tanto los de la tapa como los de la caja - son formularios, es decir, textos estructurados uniformemente que obedecen a un esquema que parte de una cesión real que se delega a determinado dios con la capacidad de realizar ofrendas para el propietario del sarcófago, como a continuación veremos.

La fórmula $h t p D j n s w$ - ofrenda que el Rey da - es la que más veces aparece en el sarcófago de Amenirdis. En cuanto a la idea que subyace "a las fórmulas htp-di-nesu es que el rey da, o tiene para dar, una ofrenda a algún dios en su templo, para que posteriormente en su momento esas ofrendas puedan ser dadas a un individuo privado en su tumba" (Gardiner, 1957, p. 172). Es muy probable que en muchos casos estas ofrendas que el rey concede sean el resultado de un automatismo, consecuencia de la lógica económica de una producción en serie de los sarcófagos.

El siguiente ejemplo ilustra la estructura formularia tal cual se representa en el sarcófago de Amenirdis: htp Dj nsw $n$ Wsjr xnty jmn.t.t $n T r$ r a $n b$ Abdw dj=fpr-xrw Apd.w snTr $m n x . t$ Ss htp.w nb.w DfA.w nb.w jrp jr.t xt nb(.t) nfr(.t) (ofrenda que da el rey a Osiris, el que preside el Occidente, dios grande, señor de Abidos, para que él dé una invocación de ofrendas (consistente en) bueyes, aves, incienso, telas, alabastro, toda clase de ofrendas, toda clase de alimentos, vino, leche, toda cosa hermosa). La misma fórmula se repite en referencia a varios dioses, respondiendo al esquema de la Figura $3^{14}{ }^{15}$.

\section{Datación y tipología de la iconografía}

Taylor (1985) propone una tipología para los sarcófagos del Período Tardío, específicamente para Tebas, lugar de procedencia del presente sarcófago. Esta tiene en consideración cuestiones técnicas, iconográficas y textuales, entre otras. Según Taylor (1985), el sarcófago de Amenirdis corresponde a Th. IV y su datación lo ubica en la Dinastía XXVI, afirmando además que se trata de un sarcófago interno ${ }^{16}$. Este es un período de transición dado que continúa con las tendencias arcaizantes de la Dinastía XXV (o Kushita). En efecto, los primeros gobernantes nubios adoptan titulaturas de los Reinos Antiguo y Medio. "El modelado del cuerpo Nubio es igualmente una innovación que inaugura un periodo de creciente realismo en el arte egipcio. Musculatura cincelada y rostros nubios 'carnosos' son las características salientes de este nuevo modelo. (...),
14. Las divinidades o grupo de divinidades a quien el rey concede una ofrenda son las siguientes: $R a$ Horus del horizonte (tres veces), Geb (tres veces, una de ellas ofrece un entierro), Osiris (ocho veces), Anubis (una vez), Horus Behdet (dos veces), Osiris Unnefer (dos veces), Osiris y Ra Horus del horizonte (dos veces), Isis (dos veces), Neftis (una vez), Ptah-Sokar-Osiris (una vez), Atum (una vez), Osiris Unnefer, Geb, Anubis Imy-ut, Anubis (una vez), Osiris, Ra Horus del horizonte, Ptah al sur de su muro, Anubis, Anubis Imy-ut (una vez), Osiris y Geb (dos veces), Osiris, Ra Horus del horizonte, Atum, Osiris Unnefer, Ptah-Sokar-Osiris, Anubis, Anubis Imy-ut, Geb (una vez), Atum, Osiris Unnefer, Anubis, Ra Horus del horizonte, Ptah-Sokar-Osiris, Anubis (una vez).

15. La incorporación en el esquema de Nespahamenu (su padre) e Irt-ru (su madre) está justificada porque cada uno de ellos, por separado o bien juntos, son mencionados como sus padres luego de la presentación de ofrendas para Amenirdis. En el caso de Nespahamenu se dice que está junto a los dioses y en el caso de Irt-ru, se la menciona como señora de la casa, es decir nb.t pr, el mismo título que Amenirdis.

16. En algunos entierros tanto reales como privados, el estilo de los sarcófagos era combinado y consistía de un sarcófago antropomorfo, uno qrsw, uno con cuatro postes y una tapa abovedada como los encontrados en el Reino Antiguo, aunque los sarcófagos antropomorfos de madera aún no eran el estilo más común (Valentine, 2013). 


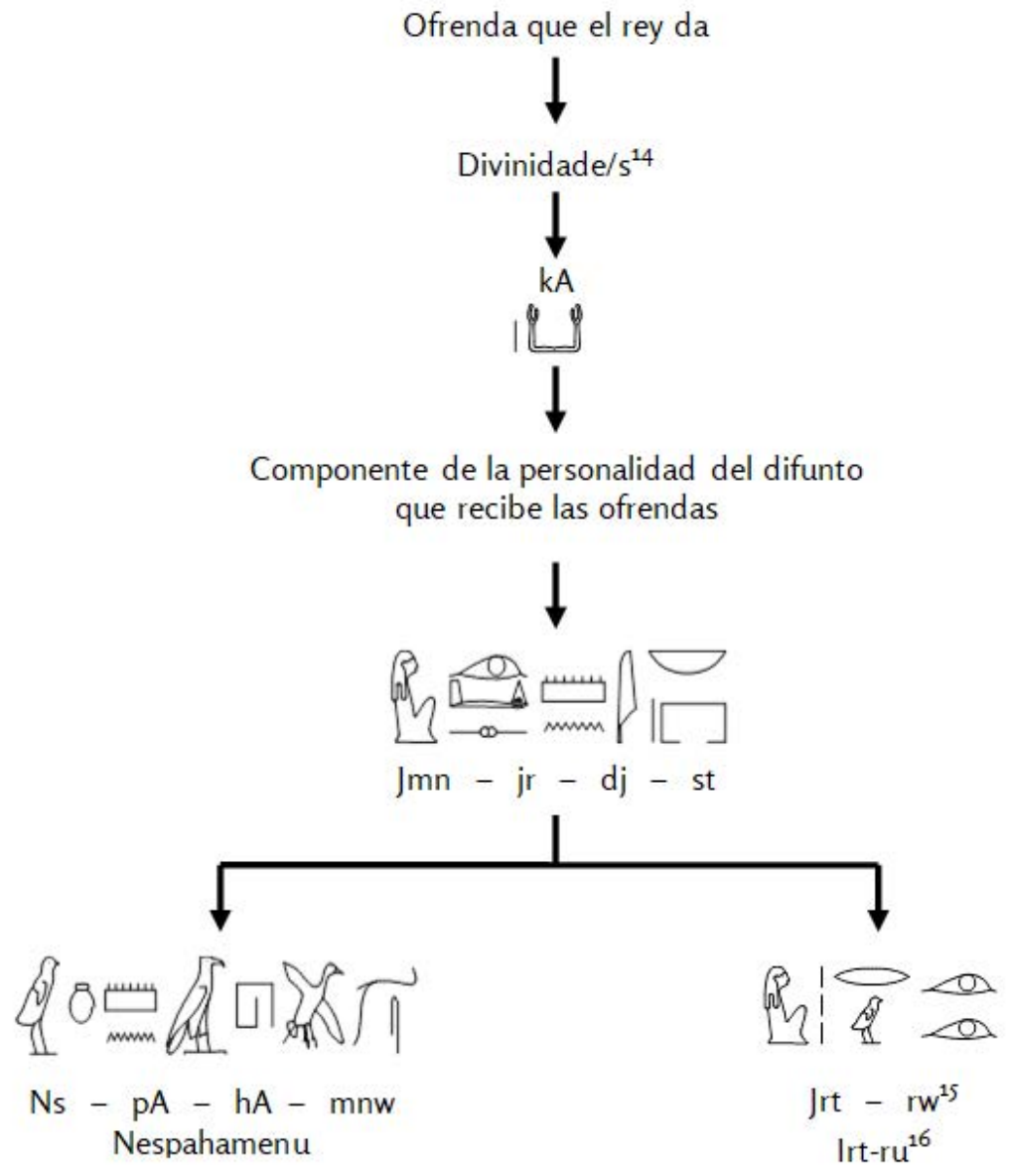

Figura 3. Esquema general de ofrendas en el sarcófago de Amenirdis.

además, se ha sugerido que la teología Kushita preparó a Egipto para la unidad lograda bajo los Saítas -Dinastía XXVI-” (Chimko, 2003, p. 46).

La Tabla 4 muestra la tipología específica para los sarcófagos tebanos junto con las características particulares de cada una de ellas. Dentro de Th. $I V$ hay una subdivisión que se sustenta en la iconografía de las tapas de los sarcófagos. Th. IVA incluye escenas con halcones solares (halcones con cabeza de carnero) representados directamente debajo del collar o bien un halcón representado con las alas desplegadas sobre el abdomen. A este tipo de diseño se lo denomina "sunrise".

La tipología Th. IVB tiene representada una figura de Nut, imagen típica de los sarcófagos bivalvos de la Dinastía XXVI (Miatello, 2018), y esta es la que le corresponde a Amenirdis. Este tipo de sarcófagos se caracteriza además por una imagen axial del denominado fetiche de Abidos o una columna djed a pequeña escala. En el sarcófago de Amenirdis tenemos representada una figura de Osiris con típica corona atef (corona blanca flanqueada con plumas de avestruz) con los brazos cruzados llevando cada uno el cetro $w A s$ y el látigo. Según Taylor (2003) hay una estrecha afinidad entre el diseño 1 (sunrise) y el 4 (incluidos IVA y IVB).

En la tapa del sarcófago, bajo la figura de Nut, se encuentran bandas de figuras horizontales entre las que se alude al Juicio a los Muertos, asimismo se encuentra la escena de la momia sobre el ataúd con el $b A$ o "con un sol resplandeciente" (Niwinski, 1983, p. 451), ambos motivos típicos de época tardía. 


\begin{tabular}{|c|c|c|}
\hline Tipo & Período & Características generales \\
\hline Th. I & Comienzos del III PPI XXI Dinastía & $\begin{array}{l}\text { Mayor profusión iconográfica que textual, motivos solares y } \\
\text { de regeneración. }\end{array}$ \\
\hline Th. II & Mediados y fines de la XXII Dinastía (dentro de Th. I) & $\begin{array}{l}\text { Se mantienen los motivos solares pero se enfatiza en la } \\
\text { protección del difunto. }\end{array}$ \\
\hline Th. III & $\begin{array}{l}\text { Fase transicional breve entre Th. II y Th. IV, luego del } 740 \\
\text { A.D. }\end{array}$ & Menor profusión textual. \\
\hline Th. IV & Desde la XXIII Dinastía hasta el Período Saíta & $\begin{array}{c}\text { Cambios en la decoración general y en la disposición } \\
\text { decorativa de sarcófagos internos. Mayor profusión de dioses } \\
\text { y nuevo énfasis en la mitología solar y en escenas del juicio. } \\
\text { Mayor textualidad y fórmulas de ofrendas. }\end{array}$ \\
\hline
\end{tabular}

Tabla 4. Tipología de los sarcófagos del III Período Intermedio según Taylor (1985, pp. 336ss.). Nota: PPI) Primer Periodo Intermedio.

$\mathrm{Al}$ igual que el lado interno de la tapa, el fondo del sarcófago está decorado con la misma figura de la diosa Nut y con 37 líneas de textos horizontales más dos laterales, todo el conjunto sobre un fondo blanco y con los textos y la representación en color negro ${ }^{17}$.

Para la Dinastía XXVI (664-525 A.D.), el repertorio de sarcófagos está plenamente establecido. En cuanto a los elementos específicos podemos mencionar: arcaísmos, motivos del Reino Antiguo y del Reino Medio interrelacionados con innovaciones; la figura de Nut bajo el collar; la figura de Nut decora el interior; Nut alada, escenas del juicio y banda horizontal de textos; Neftys es representada en la cabeza del sarcófago e Isis a la altura de los pies o en el pedestal; escenas del juicio y de la momia sobre un féretro, alternadas con bandas de columnas de textos cortos. Los sarcófagos internos representaban al muerto divinizado con nuevos elementos tomados de los cánones de la escultura — pilar trasero y pedestal— (Taylor, 2001b).

Para esta época, la regla era la decoración con escenas solares así como los cuatro hijos de Horus sobre la parte abovedada de la tapa. No obstante, la riqueza iconográfica de los sarcófagos tardíos fue disminuyendo progresivamente, lo que resulta en una mayor riqueza textual que icónica. Esta disminución de la iconografía inversamente proporcional a la profusión textual es marcada en nuestro sarcófago si tenemos en cuenta que la parte interna de la caja (a excepción de la imagen de Nut sobre el fondo) y su parte externa están repletas de inscripciones. De todos modos, ello no supone una ruptura en lo que respecta a la interacción solar-osiriana tan característica de la iconografía de estos sarcófagos, por cuanto es sobre estas representaciones ya utilizadas por la realeza que los particulares depositaban su posibilidad de pervivencia extraterrena.

La policromía de la decoración, la peluca tripartita, la pintura de columnas de texto pintadas sobre dos o tres colores de fondo alternados (verdes, rojos y azules), la mayor claridad de colores en el sarcófago interno, una renovación de motivos iconográficos que enfatizan la mitología solar y que incluyen la representación de la barca, escenas del juicio de los difuntos, profusión de fórmulas de ofrendas, la figura de Nut en la parte interna de la tapa y el fondo de la caja del sarcófago, son todos elementos presentes en Amenirdis. Exceptuado el rostro del difunto, que en el caso de las mujeres es casi invariablemente rosa (Taylor, 2001a), la superficie de la tapa es completamente amarilla, con jeroglíficos y representaciones en colores diversos.

Tanto el nombre de Amenirdis, "muy común en época tardía aunque su surgimiento se remonta a la Dinastía XXV Kushita" (von Beckerath, 1999, p. 210), como 1) la estructura del sarcófago - la caja y su respectiva tapa antropomórfica-, denominados "bivalvos"18 que son característicos de las Dinastías XXV y XXVI, 2) la figura de Nut que cubre el piso de la caja, 3) el abandono del cartonagge, típico de época libia pero que "se utiliza
17. Como EA 6272 del British Museum, cofre interno de Ankhesnefer, Dinastía XXVI (Taylor, 2001a, p. 174, pl. 55-4).
18. "Este tipo de sarcófagos refleja una superficie menor en comparación con los sarcófagos externos, que conservaban las proporciones tradicionales" (Dodson, 2015, p. 5). 
19. La tradición de los cofres anidados (nested coffins) no fue abandonada en época tardía y fue continuada con sarcófagos de madera y nuevas características estructurales innovadoras desarrolladas sobre los cofres interno y externo tales como la

base de pedestal, el zócalo trasero y el regreso de la parte superior abovedada sobre el sarcófago (Williams, 2014). El sarcófago de Amenirdis es un sarcófago interno colocado en otro mayor.

Su depositación en el suelo es una hipótesis que puede conspirar contra lo anterior, dado que si la posesión de cofres anidados suponía un lujo por su elevado costo, la depositación en el suelo del sarcófago de Amenirdis nos referiría en este caso a una posición social encumbrada por los altos costos de los cofres anidados (cuyos sarcófagos externo e intermedio podrían haber sido robados para su reutilización), aunque caemos aquí en el terreno de la hipótesis. cada vez menos a comienzos del siglo VII BC" (Taylor, 1989, p. 53), "las imágenes están pintadas en tela sobre una base de yeso" (Raven, 1981, p. 12) la estandarización del pedestal, 5) la economía textual e iconográfica en general y 6) el cofre interno ${ }^{19}$ (Taylor, 2001a) son indicadores adicionales para su datación en la Dinastía XXVI.

Otro indicio de que el sarcófago es de época tardía son los nombres que aparecen en su programa textual. El nombre del padre de Amenirdis, Nes-pa-h(a)-men(u), no aparece en el catálogo de nombres personales de Ranke (1935) aunque la primera parte del mismo, $N s$ - $p A$, se traduce como "él (o el que) pertenece a”. Esto surge de nombres con la misma estructura tales como $N s-p A-m A i$ “él (o el que) pertenece al león", $N s-p A$-miw "él (o el que) pertenece al gato", $N s-p A-n w n w$-wr "él (o el que) pertenece al gran $N u n$ " o $N s-p A-R a$ "él (o el que) pertenece a $R a$ ", entre otros, en el que $n s$ denota pertenencia (Wb II, 321) y " $p A$ es un artículo definido, típico uso del egipcio tardío” (Satzinger, 1998-1999, p. 79). La Tabla 5 da cuenta de los datos de Amenirdis surgidos de los datos textuales e iconográficos de su sarcófago.

\section{Sarcófago y depositación}

La utilización de motivos iconográficos y textuales usados por la realeza por parte de particulares se sostiene en una relación inversamente proporcional a la lejanía de estos círculos. Vale decir, una mayor distancia de los círculos de la alta élite supone una economía iconográfica que optimiza y en cierto modo sobre-explota estos recursos. En nuestro caso, y a partir de su programa textual, la falta de vinculaciones a un templo del cual pudiese ser cantante o sacerdotisa, o a tener un esposo vinculado a la realeza o al clero, colocan a Amenirdis en una situación de pertenencia a una baja élite. No obstante, el solo hecho de costearse un sarcófago posicionaba en una situación económica y social importante a quien tuviera la capacidad de hacerlo.

A la falta de una tumba propia podemos oponer el entierro (o la depositación) de Amenirdis en las cercanías de alguna tumba, dada su alta carga simbólica, y ante la carencia de un programa iconográfico de máxima - dicho esto en referencia a las viñetas secuenciales (Hartwig, 2004) de la vida diaria en el interior de la tumba-, el sarcófago mismo se erige como un centro focal que proyecta el deseo inmanente del difunto de regenerarse en el otro mundo, preservando su identidad. Los lugares de depositación de los sarcófagos varían entre su disposición sobre la superficie del terreno y en el interior de hipogeos. Ambas situaciones tienen en común la negociación de lugares por pertenencia institucional y/o parental, siendo distintas las inscripciones y la decoración que uno y otro contexto presupone (Manzi y Pereyra, 2012). Por ello, su ubicación conlleva implícita la compleja relación generada entre el difunto y los rasgos que conforman el paisaje funerario.

En referencia a los contextos de hallazgos en el paisaje tebano, los sarcófagos fueron depositados en estructuras funerarias - tumbas reales y de la elite- o sobre la superficie del terreno, dependiendo de los períodos de que se trate, entablando una compleja relación entre el difunto y el paisaje funerario socialmente construido (Manzi y Pereyra, 2012) y con la circulación de bienes y personas en el ámbito de la necrópolis (Manzi y Cerezo, 2009; Manzi y Pereyra, 2010).

La producción de sarcófagos y la abundancia decorativa se relacionaron con la disponibilidad de recursos y la posición social del propietario, así como la temática, el desarrollo y la extensión de los textos e iconografía plasmados sobre la superficie del mismo. El grado de participación del difunto que no pertenecía a la realeza en los rituales funerarios, su programa textual e iconográfico, su grado de inserción en la sociedad de los vivos — que se perpetúa luego en la sociedad de los muertos- y su 


\begin{tabular}{|l|c|}
\hline \multicolumn{2}{|c|}{ Ficha de la propietaria del Sarcófago } \\
\hline Nombre & Amenirdis \\
\hline Datación & Dinastía 26 \\
\hline Título & Señora de la Casa \\
\hline Proveniencia & Tebas (General) \\
\hline Edad & Adulta \\
\hline Status Marital & Incierto \\
\hline Etnicidad & Egipcia \\
\hline
\end{tabular}

Tabla 5. Ficha de la propietaria del sarcófago.

participación y "diálogo" con el paisaje funerario son factores que condicionan la agencia del difunto en su relación con el conjunto. Ejemplo de ello son los enterramientos superficiales encontrados en las cercanías de un lugar central de entierro de alto estatus (Taylor, 2001b).

Entendiendo al paisaje como una realidad compleja en la que se manifiestan elementos de índole material y simbólica como un patrón que conecta el comportamiento humano con tiempos y espacios particulares (Anschuetz, Wilshusen y Scheick, 2001), no solo los enterramientos sino también las tumbas en la necrópolis tebana estuvieron sin duda determinados por "consideraciones de su proximidad a un sitio sagrado particular" (Ockinga, 2007, p. 139). Su consecuencia fue la erección de ella en una de las áreas más sagradas del antiguo Egipto, que le confería propiedades particulares constituyendo un espacio ritual -Kultlandschaft- en el que complejos arquitectónicos y lugares de culto se vinculaban en modos diversos (Ullmann, 2007) convergiendo en una interacción entre el trasfondo mítico/teológico del espacio y una conceptual y física, topográfica (Rummel, 2016).

Las limitaciones espaciales que el sarcófago impone, en el caso particular de una nb.t pr como Amenirdis, condicionan el programa iconográfico, la elección de las imágenes adecuadas y la decisión sobre aquello que quiere mostrarse. Un sarcófago no debería ser ámbito de interacción con los vivos como lo es una tumba, razón por la cual representaciones sobre la vida diaria del difunto parecen vanas. En este sentido, la conjunción entre 1) la funcionalidad del sarcófago antropomorfo como vector de asimilación del difunto a Osiris, 2) la incorporación del difunto en el circuito cósmico de $R a$, plasmado en el cuarto registro con la presencia de la barca solar, 3) la relación filial entre Amenirdis y Nut/sarcófago, su madre, 4) la representación de la familia del difunto y finalmente 5) la centralidad de la figura de Osiris en la economía general de la tapa, operan como imágenes clave - key images -, verdaderos puntos focales que, contextualizados, "cuentan" los deseos del difunto.

\section{Conclusiones}

Hemos presentado algunas de las características más importantes de una de las piezas de la colección egipcia del Museo Etnográfico. Su programa iconográfico y textual da cuenta de su pertenencia geográfica y temporal, por lo que hemos logrado darle una tipología precisa. El estudio de sarcófagos de individuos no-reales pertenecientes a estratos por fuera de las altas elites aporta información adicional, por cuanto los estudios tradicionales del arte funerario se han concentrado primariamente en los objetos de la alta elite. Las presiones socioeconómicas y religiosas estimulaban a la 
mayoría de los niveles de la sociedad egipcia, sino todos, a preparar algún tipo de material funerario para su entierro, "aún si el enterramiento consistiera sólo en una estera de caña y un pequeño espacio en un pozo comunal” (Cooney, 2007, p. 5). En relación a ello, es importante tener en cuenta que desde la Dinastía XXV e incluso más temprano, "grupos familiares eran enterrados en viejas tumbas" (Taylor, 2001b, p. 29). Lo que se conoce respecto de la ascendencia de Amenirdis surge a partir de la exigua información que puede extraerse del estudio epigráfico del sarcófago.

El análisis del sarcófago de una $n b . t p r$, sin más alusión que a su propio nombre, al de su padre y al de su madre, supone que surjan cuestiones particulares a la hora de su análisis, entre las cuales sin lugar a dudas la limitación en los recursos que obligaban a la realización de una economía textual como iconográfica sintética que comprenda los elementos tendientes a la transfiguración optimizando esos escasos recursos, deviene en central. Esta limitación de ciertos sectores de la sociedad egipcia no solo condicionaba la elección textual e iconográfica, sino también la capacidad de darle a su sarcófago una ubicación en una tumba, de pozo comunal o de cercanía a algún templo u otra tumba.

\section{Agradecimientos}

Quiero agradecer en primer lugar a los evaluadores anónimos de este artículo, quienes con sus valiosos comentarios, críticas y/o sugerencias contribuyeron a la mejora sustancial de la versión original. Luego, a la Dra. María Violeta Pereyra, quien con su inagotable generosidad y vasta experiencia me da las herramientas para tratar de superarme diariamente.

El presente artículo es resultado de la Estancia Posdoctoral en Ciencias Humanas y Sociales en la Facultad de Filosofía y Letras, Universidad de Buenos Aires. Título del Proyecto: "El sarcófago como espacio de transfiguración funeraria". Análisis vinculado al Proyecto UBACyT 20020120100344BA (Programación 2013-2016) titulado "Huellas en el paisaje. Constructos histórico-culturales, del Éufrates al Nilo", dirigido por la Dra. M. Violeta Pereyra y radicado en el Instituto de Historia Antigua Oriental "Abraham Rosenvasser". 


\section{Q Referencias citadas}

" Anschuetz, K., Wilhusen, R. y Scheick, Ch. (2001). An archaeology of landscapes: perspectives and directions. Journal of Archaeological Research, 9(2), 157-211.

"Bettum, A. (2014). The Principle of Nesting in Elite Burials and Religious Art. Ancient Egyptian Coffins: Craft Traditions and Functionality. Abstracts of the Annual Egyptology Colloquium.

" Cooney, K. (2007). The Cost of Death. The Social and Economic Value of Ancient Egyptian Funerary Art in the Ramesside Period. Leiden: Nederlands Instituut voor het Nabije Oosten.

" Cooney, K. (2010). Gender transformation and the Egyptian coffin: a Ramesside case study. Near Eastern Archaeology, 73(4), 224-237.

»Cooney, K. (2014). Coffins, cartonnage, and sarcophagi. En M. Hartwig (Ed.), A Companion to Ancient Egyptian Art (pp. 269-292). West Sussex: Willey Blackwell.

»Chimko, C. (2003). Foreigns pharaohs: self-legitimization and indigenous reaction in art and literature. Journal of the Society for the Study of Egyptian Antiquities, 30, 15-57.

"Chiou, D. y Sowada, K. (2009). A coffin of imported conifer wood from Saite Period Saqqara. Bulletin of the Australian Centre for Egyptology, 20, 27-36.

"Dodson, A. (2015). Ancient Egyptian Coffins: the Medelhavsmusset Collection. http://www. varldskulturmuseerna.se/Documents/Medelhavet/Ancient\%20Egyptian\%20Coffins_ low.pdf. (Acceso: 15 de febrero, 2017).

"Elias, J. P. (2014). Gods at all hours: Saite Periods coffins of the "eleven-eleven" type". En Rogério Sousa (Ed.) Body, Cosmos and Eternity: New Trends of Research on Iconography and Symbolism of Ancient Egyptian Coffins (pp. 122-133). Oxford: Archaeopress.

»Figueiredo, A. (2005). The cartonagge mummy-case of Irtieru (Egyptian Collection, Museu Nacional de Arqueologia): a reassessment. O Arqueòlogo Português, Serie IV, (23), 437-449.

» Fuscaldo, P. (1972). El ataúd de Amenardis. Revista del Instituto de Historia Antigua Oriental, 1, 65-98.

» Gardiner, A. (1957). Egyptian Grammar. Being an Introduction to the Study of Hieroglyphs. Oxford: Griffith Institute.

》Grallert, S. (2007). The Mitre Inscriptions on coffins of the Middle Kingdom: a new set of texts for rectangular coffins. En S. Grallert y W. Grajetzki (Eds.), Life and Afterlife in Ancient Egypt during the Middle Kingdom and Second Intermediate Period, (pp.35-8o). Londres: Golden House Publications 7.

» Greco, Ch. (2014). The Tomb of Ramose. En E. Pischikova, J. Budka y K. Griffin (Eds.), Thebes in the First Millennium BC (pp. 173-200). Cambridge: Cambridge Scholars Publishing.

"Green, L. (1988). Queens and princess of the Amarna Period: the social, political, religious and cultic role of the women of the royal family at the end of the eighteenth dynasty (Tesis de Doctorado inédita), Universidad de Toronto, Estados Unidos.

》 Hartwig, M. (2004). Tomb Painting and Identity in Ancient Egypt, 1419-1372. Brespols: Fondation égyptologique reine Elisabeth. 
》 Küffer, A. (2012). Zur Bedeutung des Sarges im Alten Ägypten. http://www.e-coffins.ch/ images/stories/PDF/Bedeutung\%2odes\%20Sarges.pdf. (Acceso: 2 de julio, 2017).

" Lacovara, P. (2007). A Rishi Coffin from Giza and the Development of this Type of Mummy Case. En Z. Hawass y J. Richardt (Eds.), The Archaeology and Art of Ancient Egypt. Essays in Honor of David B. O'Connor. Annales du Service des Antiquitès de L'Ègypte Cahier № 36 Vol. II (pp. 33-38). El Cairo: Publications du Conseil Suprême des Antiquités de L’Egypte.

" Magdolen, D. (2015). The Ancient Egyptian coffin in the Slovak National Museum: the decorative motives on the external surface of the pedestal. Asian and African Studies, 24(2), 233-246.

" Manzi, L. y Cerezo, M. (2009). Proceso de ocupación y reocupación del espacio: la colina de el-Khokha y los templos de Tebas occidental, Egipto. Trabajo presentado en las XII Jornadas Interescuelas. San Carlos de Bariloche.

» Manzi, L. y Pereyra, M. (2010). La muerte en el más allá y su negación en el aquí y ahora a través de la construcción de paisajes culturales. Anais do IV Congresso Latinoamericano de Ciencias Sociais e Humanidades, 39-62, Niteroi.

» Manzi, L. y Pereyra, M. (2012). La jerarquización del espacio a través de la distribución de tumbas privadas en Tebas Occidental, Egipto. Novos Trabalhos de Egiptologia Ibérica, $1,637-655$.

»Miatello, L. (2018). Examining texts and decoration of Peftjauauiaset's coffins in Milan. Égypte Nilotique et Méditerranéenne, 11, 41-133.

» Miniaci, G. (2007). Some Remarks on the Development of rishi Coffins. En S. Grallert y W. Grajetzki (Eds.), Life and Afterlife in the Middle Kingdom and Second Intermediate Period (pp. 94-99). Londres: Golden House Publications.

"Miniaci, G. (2010). The iconography of the Rishi coffins and the legacy of the Late Middle Kingdom. Journal of Ancient Research Center in Egypt, 46, 49-61.

» Niwinski, A. (1983). Sarg NR-SpZt. En W. Helck, E. Otto y W. Westendorf (Eds.), Lexikon der Ägyptologie V (pp. 434-468). Wiesbaden: Otto Harrassowitz.

" Ockinga, B. (2007). Use, reuse and abuse of "sacred space": observations from Dra Abu el-Naga. Studies in Ancient Oriental Civilization, 61, 139-162.

»Piankoff, A. (1934). The Sky-Goddess and the Night Journey of the Sun. Journal of Egyptian Archaeology, 20(1/2), 57-61.

» Ranke, H. (1935). Die Ägyptischen Personennamen. Glückstadt: J.J. Augustin.

" Raven, M. (1981). On some coffins of Besenmut family. Oudheidkundige Mededelingen uit her Rijkmuseum van Oudheden te Leiden, 62, 7-21.

» Rummel, U. (2016). Der Leib der Göttin: Materialität und Semantik ägyptischer Felslandschaft. En S. Beck, B. Backes, L. I-Tingo, H. Simon y A. Verbosek (Eds.), Gebauter Raum: Architektur-Landschaft-Mensch, Göttinger Orientforschungen 62 (pp. 42-74). Wiesbaden: Otto Harrassowitz.

"Santos, D. (2003). La colección egipcia del Museo Etnográfico de Buenos Aires. Ataúd de Amenirdis, primera parte. Aegyptus Antiqua, 11, 11-42.

»Santos, D. (2007). La colección egipcia del Museo Etnográfico de Buenos Aires. Ataúd de Amenirdis, segunda parte. Aegyptus Antiqua, 12, 12-49.

» Satzinger, H. 1988-1989. Reading Late Egyptian. Revue Roumaine d'Egyptologie, 2-3, 77-83.

"Sousa, R. (2011). O rosto misterioso. Memória material num objecto anónimo de uma Sacerdotisa de Amon. (Ataúde A.4 da Sociedade de Geografía de Lisboa). Revista do Centro de Investigação Trandisciplinar Cultura, Espacio y Memoria, 2, 231-244. 
» Taylor, J. (1985). The development of Theban coffins during the Third Intermediate Period: a typological study. (Tesis de Doctorado inédita), Universidad de Birmingham.

» Taylor, J. (1989). Egyptian Coffins. Shire Egyptology Series 11. Aylesbury: Cromwell House.

» Taylor, J. (2001a). Patterns of colouring on ancient Egyptian coffins from the New Kingdom to the 26th dynasty: an overview. En W. Davies (Ed.), Colour and Painting in Ancient Egypt (pp. 164-181). Londres: British Museum Press.

» Taylor, J. (2001b). Death and Afterlife in Ancient Egypt. Chicago: University of Chicago.

» Taylor, J. (2003). Theban coffins from the Twenty-second to the Twenty-sixth Dynasty, dating and synthesis of development. En N. Strudwick y J. Taylor (Eds.), The Theban Necropolis. Past, Present and Future (pp. 95-119). Londres: British Museum.

»Ullmann, M. (2007). Thebes: origins of a ritual landscape. Studies in Ancient Oriental Civilization, 61, 3-25.

»Valentine, M. (2013). An examination of a coffin fragment in the Collection of the Institute of Egyptian Art and Archaeology at the University of Memphis (1994.4.9). (Tesis de Grado inédita), Universidad de Menfis, Estados Unidos de América.

» von Beckerah, J. (1999). Handbuch der Ägyptischen Königsnamen. Munchner Ägyptologische Studien 49. Munch: Von Zabern.

»Williams, A. (2014). Tradition and archaism in 25th and 26th Dynasty coffins. Poster presentado en el First Vatican Coffin Conference. Ciudad del Vaticano. 